\title{
Ritos funerarios católicos en el Valle Central de la Costa Rica del siglo XIX
}

\author{
Patricia Fernández Esquivel* \\ Manuel Chacón Hidalgo**
}

\begin{abstract}
RESUMEN
El estudio de la muerte en Costa Rica ha sido abordado por historiadores sobre todo para los siglos XVII, XVIII y por antropólogos para el siglo XX. El siglo XIX no ha sido objeto de estudios profundos que analicen los ritos funerarios y su significado social. En este trabajo se hace una revisión exploratoria con algunas fuentes primarias pero sobre todo con fuentes secundarias, acerca de algunos ritos funerarios católicos característicos del siglo XIX y algunos de los cambios que se dieron en ellos a lo largo del siglo en estudio.
\end{abstract}

Palabras clave: Ritos funerarios católicos, siglo XIX, Valle Central de Costa Rica.

\begin{abstract}
The death study in Costa Rica has been dealt by historians mostly on the XVII, $X V I I I$ century and also by anthropologists on the XX century. The XIX century has not been an aim of intense study on funerary rituals and their meaning towards society. On this project, an exploratory revision is made with a few primary sources, but it is mostly based on secondary sources, these are about some of the funerary catholic characteristic rituals of the XIX century and some of the changes that occurred on these rituals throughout this period of time.
\end{abstract}

Keywords: Funerary catholic rituals, XIX century, Costa Rica's Central Valley.

\section{Introducción}

La representación y las actitudes del hombre ante la muerte (costumbres, mitos, creencias, ritos) han sido muy diferentes en distintas épocas y en distintas sociedades. Es por esto que la muerte es mucho más que una cuestión médico científica y que por todas sus implicancias culturales particulares, debe ser entendida como una construcción social e histórica.

\footnotetext{
* Patricia Fernández Esquivel. Costarricense. Licenciada en Antropología con énfasis en Arqueología y candidata a Magíster en Antropología. Fundación Museos Banco Central de Costa Rica, fernandezep@bccr.fi.cr

${ }^{* *}$ Manuel Chacón Hidalgo. Costarricense. Historiador y candidato a Magíster en Historia. Fundación Museos Banco Central de Costa Rica, chaconhm@bccr.fi.cr
} 
La muerte es un hecho que está rodeado de una serie de manifestaciones que son producto de creencias, contextos socioeconómicos, culturales, espaciales y temporales. Para el caso del Valle Central de la Costa Rica del siglo XIX, los ritos funerarios tienen lugar dentro de un contexto con concepciones religiosas y sociales particulares sobre el significado de la muerte. En esta sociedad, fundamentalmente católica, la muerte es un mecanismo que permite la transmisión de tradiciones y percepciones sociales que varían en función de los contextos socioeconómicos y políticos.

\section{La continuidad colonial 1801-1814}

Los primeros años del siglo XIX se van a caracterizar por la continuidad de los ritos funerarios de los siglos anteriores. Esta etapa forma parte del período colonial.

La referencia más temprana del siglo XIX sobre ritos funerarios la proporcionó el gobernador Tomás de Acosta en 1801, cuando éste informa al presidente de Guatemala sobre las pompas fúnebres y toques de campanas en la ciudad de Cartago. A partir de su descripción podemos conocer varias características del rito funerario: "El cadáver se conduce en una cuna pintada de blanco, la carpeta que le tapa es de algodón teñido de negro, no lleva cojines bajo la cabeza sino sus propias almohadas que tenía en la cama antes de morir." (Tomás de Acosta. 1801. En: Fernández , 1976: 180).

Los trabajos de Carmela Velásquez para los siglos XVII - XVIII y el de Arnaldo Moya para el Cartago del siglo XVIII y principios del XIX, hacen referencia acerca de la diferenciación relacionado con la posición social del individuo. Estos investigadores se basaron en los testamentos para identificar los rituales de grupos económica y socialmente dominantes, por lo que no hacen referencia a los rituales de los sectores pobres, dada la limitación de las fuentes utilizadas ya que sólo testaban aquellos que tenían bienes.

Conocemos, además, por referencias de excavaciones realizadas en otros países en cementerios coloniales, así como el llevado a cabo en la Catedral Metropolitana de Costa Rica, que como continuidad de las prácticas funerarias que se practicaban desde inicios de la colonia, se mantuvo hasta la primera mitad del siglo XIX la costumbre inhumar a los files en el interior del templo siempre y cuando fueran vecinos distinguidos de la localidad, dado que los pobres se enterraban a las afueras del templo.

Los españoles introdujeron en sus colonias de América la práctica de enterrar a sus muertos en el interior de las iglesias cuando los familiares del difunto podían pagar esta distinción, o en un patio inmediato al templo cuando el muerto pertenecía a las clases pobres (Barros, 1911: 227). En este sentido, consideramos que el concepto de cementerio o camposanto incluía el templo y sus terrenos aledaños. Las fosas funerarias se ubicaban tanto dentro como fuera del templo por lo que la ubicación del difunto dependía de su condición social y capacidad económica.

El origen de esta práctica se ubica a pocos siglos de surgido el cristianismo. Alfonso X, el sabio, explicó esta práctica en la Ley $2^{\mathrm{a}}$, Título XIII, de su Código, aduciendo para ello cuatro razones: la primera por considerarse que al estar enterrado dentro de la iglesia había una mayor cercanía a 
Dios, la segunda, porque al ir los individuos a la iglesia y ver las tumbas de sus parientes o sus amigos se acuerdan de rogar a Dios por ellos; la tercera, porque los difuntos se encomiendan a los santos en cuya honra fueron fundadas las iglesias; y la cuarta, porque los diablos no pueden llegar a los cuerpos enterrados en las iglesias.

Alfonso $\mathrm{X}$ también definió quiénes podían ser enterrados en las iglesias como los reyes, reinas y sus hijos; los obispos, los abades, los priores, los maestres, los prelados de las órdenes conventuales, hombres ricos, hombres honrados que hiciesen iglesias y monasterios y todos aquellos que fueran reconocidos por su santidad, buena vida y obras. (Barros, 1911: 227-228). En Costa Rica esta costumbre prevaleció hasta el siglo XIX, tal y como lo demuestran los trabajos de Carmela Velásquez (1996) y de Ricardo Vázquez (1999).

Los patrones de enterramiento se caracterizaron por el depósito directo del cadáver en una fosa en la tierra, la cual podía estar ubicada en el interior de la iglesia o en la parte externa de la misma. Los fieles con mayor poder económico, por lo general pedían ser enterrados dentro de la iglesia contra pago de una cantidad de dinero, condición que quedaba estipulada en los testamentos, mientras que otros con menos capacidad económica o pobres eran enterrados en las afueras de la iglesia (Velásquez, 1996).

Con lo anterior podemos ver, que la escala social que los difuntos habían tenido en vida se reflejaba en la ubicación diferenciada de los enterramientos. Esta práctica cambiaría después de 1814 cuando se estableció la prohibición de las inhumaciones al interior de las iglesias.

Pasado el enterramiento, se realizaban rezos por el alma del difunto en los días posteriores. Para ello se hacía una especie de altar en la casa caracterizado por la utilización de telas negras y una cantidad importante de velas. El pueblo era convocado a asistir al rezo diario por medio de las campanas de la iglesia (Fernández, 1976: 180).

\section{Cambio en los patrones de enterramiento: los cementerios fuera de los poblados 1814- 1884}

Por razones sanitarias, desde 1792 la corona española planteó la necesidad de reubicar los cementerios fuera del centro de las poblaciones. La práctica de ubicar los cementerios dentro de las ciudades fue abolida en el siglo XIX, por Real Orden del 6 de Noviembre de 1813, por lo que se mandó a ubicar los cementerios fuera de las poblaciones.

En Costa Rica, esta disposición fue cumplida con prontitud y en setiembre de 1814 el Gobernador Ayala comunica al Capitán General de Guatemala un listado de las poblaciones donde los cementerios habían sido trasladados a las afueras del centro de las poblaciones (http://www.jps.go.cr, 2005).

Los cementerios continuaron siendo administrados por la iglesia católica y los rituales mortuorios mantuvieron las características básicas en cuanto a la extremaunción, bendición del difunto en el templo, pero cambiaron algunos de los patrones de enterramiento. 


\subsection{La extremaunción}

En este período, al igual que durante el siglo XVIII y los primeros años del siglo XIX, el rito de la muerte empezaba con aquel ligado a la agonía, es decir, el de la extremaunción. Con el sacramento de la unción de los enfermos la Iglesia acude en ayuda de sus fieles que empiezan a estar en peligro de muerte por enfermedad grave o vejez. Además, "la Extremaunción quita los últimos restos de la fragilidad humana y prepara nuestra alma para la vida eterna" (http://www.enciclopediacatolica.com, 2005).

En la década de 1830, el rito de la extremaunción iniciaba con la búsqueda del sacerdote para aplicar los santos óleos al enfermo en peligro de muerte. El sacerdote, precedido por una cruz, era llevado a la casa del moribundo en andas, un tipo de silla la cual era cargada por cuatro personas gracias a un par de piezas de madera, horizontales y paralelas, adosadas a las patas de la silla. Desde la salida de la iglesia se establecía una procesión acompañada de música de violines $\mathrm{y}$ violoncelos y mujeres que rezan, que anunciaba a los habitantes que uno de sus vecinos posiblemente agonizaba (Wagner y Scherzer, 1974: 231-232). A su paso, la procesión provocaba el respecto de los fieles quienes se arrodillaban y se quitaban el sombrero como un acto de reverencia y respeto. En la casa del enfermo, el sacerdote era esperado con un arco de flores a la entrada (Stephens, 2002: 48).

Ante la inminencia de la muerte de un individuo, la iglesia católica proveía el medio para enfrentar la transición hacia el más allá con la extremaunción. A la familia le facilitaba el desprendimiento emocional, convirtiéndose este acto en un rito de transición que garantizaba un "buen morir" y una esperanza de una mejor vida después de la muerte.

\subsection{La vela}

Al fallecer el individuo este era velado en su casa. Sobre el suelo se tendía un petate con cuatro "hachones" o bases que los hacían de vástagos de plátano donde se colocaban cuatro candelas de sebo. Se traía un rezador que durante toda la noche rezaba varios rosarios que llamaban salterio y cantaban alabados muy tristes. De cuando en cuando se repartía una copa de guaro y chicha entre la concurrencia, servida en un guacal. Al otro día llevaban el cadáver a la iglesia para después ser enterrado (Álbum de Figueroa, s. f.: folio 27).

Si el difunto era un niño, este se consideraba un ángel. En estos velorios, en lugar de tristeza todo era alegría; se bailaba se bebía chicha y guaro y se repartía comida al considerarse que el cielo había ganado un nuevo ángel. Todas las visitas felicitaban a los familiares por tener la dicha de tener un hijo en el cielo. El niño era vestido con alas de querubín; sobre una mesa tendían manteles con cuatro candelas a lo lados y allí era colocado el cadáver que era adornado con flores y espejos. La vela duraba toda la noche hasta el amanecer, se hacían estallar bombetas, había música de guitarras y violines (Álbum de Figueroa. s.f.: folio 27).

Las características de los velorios dependían de la capacidad económica del difunto y los dolientes. Las variaciones se daban sobre todo en la utilización de músicos, de pólvora, en el 
licor, la comida que se repartía y el atuendo con que se vestía el difunto, tanto si eran adultos o niños.

\subsection{El cortejo fúnebre}

Aquel que pasaba a mejor vida era llevado a la iglesia para ser bendecido con agua, cantarle un responso u oficiarle una misa rezada; luego era trasladado al cementerio, ubicado de acuerdo a los vientos del lugar fuera del centro del poblado, contrario al período anterior de 1801-1814 en que el individuo se enterraba dentro del templo o en las afueras a un costado de él.

Existía una clara diferenciación socioeconómica que se expresaba en el rito mortuorio. Si el difunto era de escasos recursos se llevaba a la iglesia para ser bendecido con agua y cantarle un responso (Álbum de Figueroa. s.f.: folio 25). El traslado, tanto a la iglesia como al cementerio, se realizaba, en unas andas, especie de camilla de madera, algunas pintadas de blanco y otras decoradas las cuales pertenecían a la iglesia.

Con el cuerpo cubierto por una sábana, se realizaba una especie de procesión que era acompañada por los dolientes, música de violines y violoncelos y sin compañía de un sacerdote. Si se quería que el sacerdote estuviera presente durante el cortejo, había que pagarle. Llegado al cementerio, el cuerpo era depositado en una fosa, envuelto en una sábana, algunas veces con un crucifijo sobre su pecho y las manos sobre él. Las andas eran regresadas a la iglesia (Marr, 2002: 148; Wagner y Scherzer, 1974: 233).

Por otro lado, quienes tenían mayores recursos económicos eran llevados a la iglesia y se les pagaba una misa rezada (Álbum de Figueroa. s.f.: folio 27), no eran enterrados directamente en el suelo, sino que se utilizaban ataúdes que se colocaban en sepulturas o nichos superficiales con paredes posiblemente de calicanto, construidos en hileras y colocados unos encima de otros. Además, si se quería que el sacerdote acompañara el cortejo fúnebre al cementerio se le debía pagar una buena cantidad de dinero (Wagner y Scherzer, 1974:234).

El traslado de los cementerios del interior de las iglesias y sus alrededores afuera de de los centros de población implicó una adopción de nuevos símbolos de estatus para los difuntos. En el período 1801-1814 los enterramientos de los ricos con respecto al de los pobres se diferenciaban por su posición dentro de la iglesia y por su cercanía al altar, mientras que en el período posterior, 1814-1884 se va a caracterizar por la complejidad de la tumba. Mientras que a los pobres se les va a enterrar en el suelo directo, los ricos empezaron a construir tumbas superficiales como una muestra material de la diferenciación socioeconómica.

Ricos y pobres debían pagar un derecho -llamado "la fábrica" -, pues en caso contrario no podían obtener permiso para ser enterrados (Álbum de Figueroa. s.f.: folio 25).

Mientras que en los enterramientos de los pobres la tumba se indicaba por medio de una sencilla cruz de madera, los más pudientes lo hacían con un epitafio en la tumba que contenía, por lo general, el nombre del individuo y la edad, a lo cual a veces se agregaba una súplica para que se rezara por ellos un Padre Nuestro o un Ave María. El costo de una sepultura iba de los 10 a los 
40 pesos (Wagner y Scherzer, 1974: 233), lo que para la época representaba un monto importante si tomamos en cuenta que para 1856 el salario mensual de un jornalero era de15 pesos al mes (Molina, 1991: 206).

Después del entierro, los acompañantes volvían a la casa de los dolientes para dar su pésame. En la casa del difunto se colocaba en media sala una tela negra sobre el suelo, flanqueada por cuatro hachones y sus candelas. Allí se cantaba un responso con música, tras lo cual se servía licor, por lo general guaro, y una bebida llamada mistela, hecha a base de guaro, canela y dulce, a la cual se le daba un color rojo con un ingrediente llamado mercolina (Álbum de Figueroa. s.f.: folio 26). Este tipo de preparado todavía se consume en las celebraciones campesinas del Valle Central de Costa Rica y es llamado compuesto.

El enterramiento de un niño tenía un ritual similar al del adulto, aunque este era visto de manera diferente. En vez de tristeza había alegría ya que se consideraba que al morir a temprana edad el niño iba directo al cielo. La música era parte también del cortejo fúnebre (Stephens, 2002: 59).

\section{Figura 1 \\ Dibujo que muestra el cortejo fúnebre de un niño, según dibujo de José María Figueroa de la segunda mitad del siglo XIX}

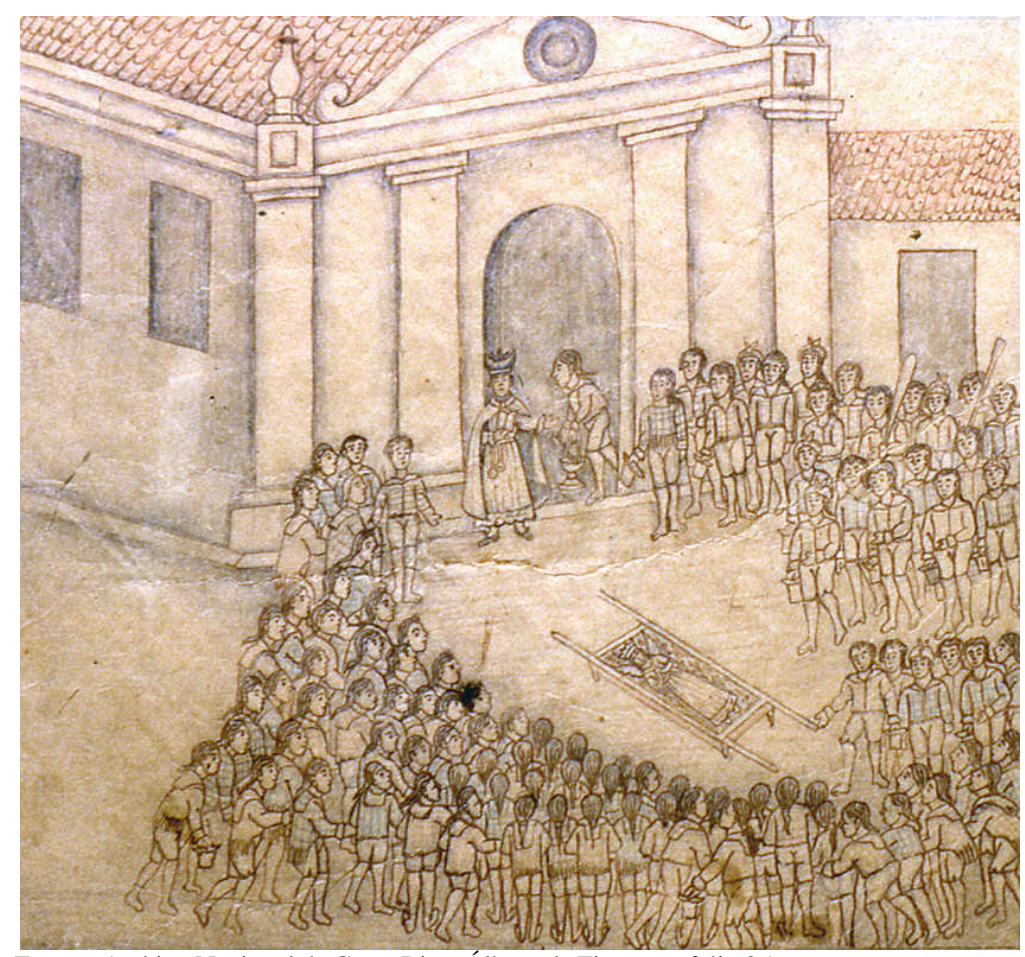

Fuente: Archivo Nacional de Costa Rica, Álbum de Figueroa, folio 25. 
Thomas Francis Meagher describe en 1859 un entierro presenciado en un viaje de San José a Cartago en 1858, en el cual la música incluía flautas y mujeres tirando flores al paso del cortejo y el acompañamiento de un sacerdote llevado en andas (Meagher, 2002: 341).

Por la complejidad y cantidad de elementos de este sepelio, es posible que se tratara de un niño cuyos padres tenían una posición socioeconómica mayor. Al igual que los enterramientos de los adultos, los de los niños denotaban también diferencias socioeconómicas.

En el siglo XIX era vista como natural la muerte de los niños, de hecho existía la costumbre de no darles nombres a los niños al nacer hasta ver si iba a sobrevivir. Esta actitud de resignación ante la muerte de los niños se justificaba debido a la alta mortalidad infantil de la época que hacía ver la muerte de un niño a muy temprana edad algo más que natural y justificada al considerarse que por su inocencia no tenía pecados que descontar en el purgatorio, por lo que su viaje al cielo era directo, siempre y cuando hubiese sido bautizado.

Como ejemplo de la alta mortalidad infantil, sólo en los primeros seis meses del año 1845 murieron 604 niños mientras que los muertos en adultos ascendió a 429, lo cual nos indica que del total de fallecidos (1033 individuos), el 58.47\% estuvo compuesto por niños, contra un 41.53 $\%$ de adultos (El Mentor Costarricense, 1845: 61)

\subsection{Los novenarios}

Después de enterrado el difunto durante nueve días se realizaban rezos en la casa, para lo cual se montaba una especie de altar llamado "tumba", compuesto por unas mesas puestas una encima de otra, la más grande abajo y la más pequeña arriba, cubiertas con telas negras. La superior de forma redonda era llamada "tumbilla" a la cual se le ponía encima una cruz de papel y tres candelas. En la mesa de debajo de esta se representaban las ánimas benditas del purgatorio, mientras que en la mesa base se pegaban una o más calaveras de papel a la tela negra. Debajo de estas se colocaba la del doliente pidiendo a Dios por el alma del difunto y debajo de esta las calaveras con los fémures cruzados (Álbum de Figueroa. s.f.: folio 26).

Es importante recalcar que el cráneo cruzado por dos fémures fue diseñado por los teólogos de la Iglesia durante el medioevo para simbolizar al padre Adán y con él la mortalidad de todos los hombres. La calavera se convirtió en un ícono utilizado en la base de todas las cruces que representan el triunfo de la Santa Cruz sobre la muerte. De ahí que la utilización de este ícono en las tumbas durante los novenarios simbolizara el triunfo de la vida eterna sobre la muerte.

La tumba en su conjunto representa tres momentos del paso del individuo hacia la vida eterna: en la base, la muerte que es representada por las calaveras; en el medio se representan las ánimas benditas del purgatorio, tránsito en que el individuo descuenta los pecados cometidos en la vida y que es ayudado a superar por el rezo de los dolientes y los acompañantes; y en la parte superior, llamada "tumbilla", en la cual se coloca una cruz que representa el triunfo de esta sobre la muerte y por tanto la vida eterna, siendo este el último estadío que todo católico desea alcanzar al morir. 


\section{Figura 2}

\section{Dibujo que muestra una tumbilla erigida en la sala de una casa, según dibujo de José María Figueroa de la segunda mitad del siglo XIX}

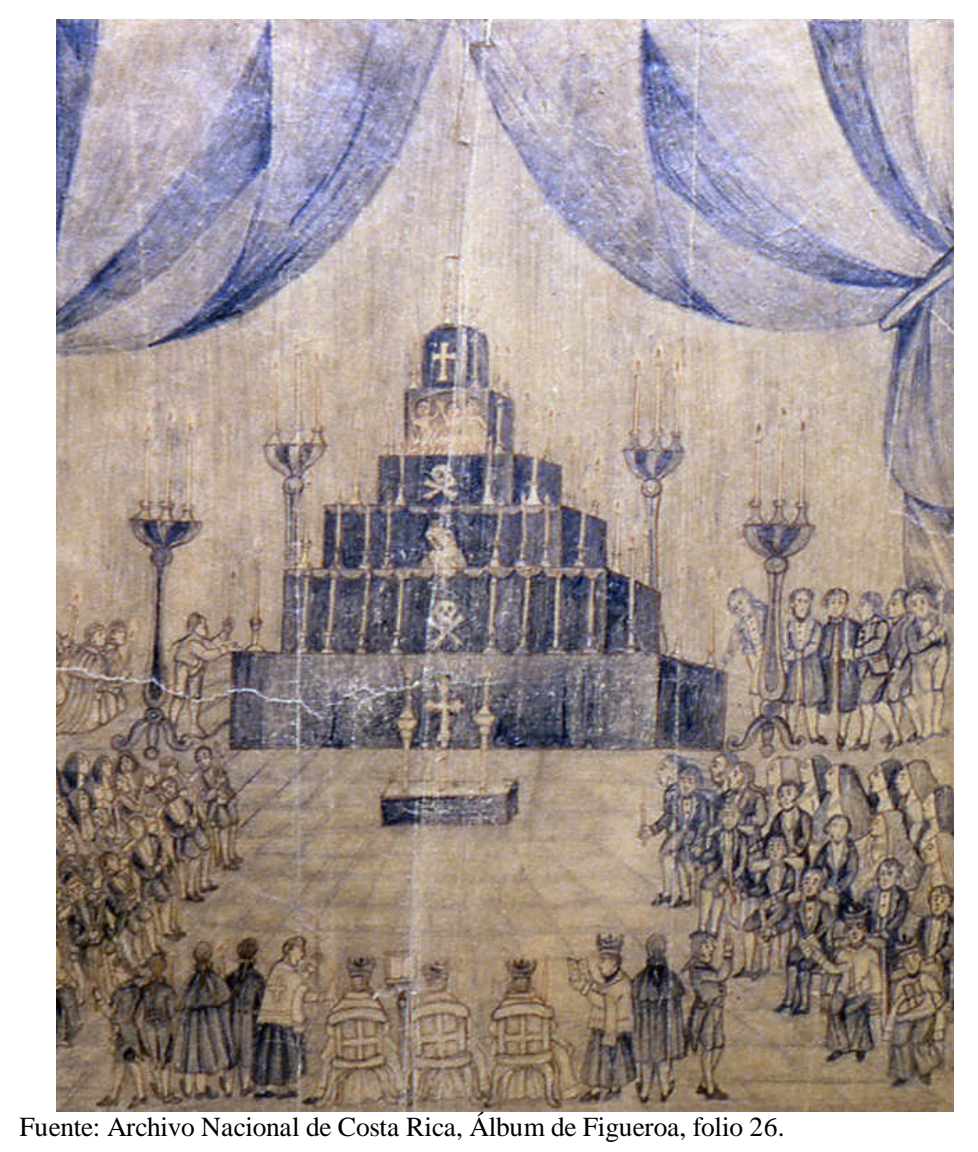

Quienes tenían mayores posibilidades económicas volvían a construir la tumbilla y realizaban rezos y misas al cabo de dos o tres años por el alma del difunto (Álbum de Figueroa. s.f.: folio 26)

Posiblemente, este concepto de tumba se trasladó a lo que conocemos como nichos en los cementerios. El nicho, construido superficialmente, por lo general se caracterizaba por el depósito del cadáver en la parte de abajo y en la superior la colocación de una cruz.

\subsection{Las necrologías}

En la década de 1840 se introdujo otro elemento de diferenciación social a nivel de los ritos funerarios. En el periódico El Mentor Costarricense de la década de 1840 aparecen las necrologías, las cuales eran semblanzas que se escribían sobre ciudadanos que habían fallecido, 
que incluían una pequeña biografía sobre los aportes de éste a la comunidad y que expresaba el dolor de la sociedad por la sensible pérdida (El Mentor Costarricense, 1843: 143).

\subsection{La celebración del día de los difuntos}

Durante la celebración del día de los difuntos, no era común adornar las tumbas con flores, más bien se quitaban las hierbas y flores silvestres que crecían en los cementerios. Frente a las tumbas se congregaban grupos de personas, mayoritariamente mujeres, que rezaban por el alma del difunto. Aquellos dolientes con mayor capacidad económica pagaban al cura que se encontraba en el cementerio medio real por cada plegaria que dijera (Wagner y Scherzer, 1974:234).

\subsection{Causas por las que un católico no podía ser enterrado en el cementerio católico}

Existían varias causas por las que los feligreses no podían ser enterrados en los cementerios católicos. Una de ellas era si se demostraba que habían muerto impenitentes o en estado de pecado, por ejemplo, en estado de ebriedad o en caso de suicidio. Para determinar esto, las autoridades civiles recopilaban la información necesaria que utilizarían los representantes de la iglesia para determinar si el individuo podía o no ser enterrado en el cementerio católico. El no estar enterrado en "tierra santa" creaba "las condiciones para que muchas almas vagaran penando” (González, 1996: 118).

Otros que corrían el riesgo de no ser enterrados en cementerios católicos eran los niños que nacían muertos o morían poco tiempo después de nacer, sin ser bautizados. Por esta razón, los padres se apresuraban a aplicarles el sacramento del bautismo, en una época en la que la mortalidad infantil era muy alta (González, 1996: 119).

\subsection{El enterramiento de extranjeros y percepción religiosa católica de los "no creyentes"}

Durante la mayor parte del siglo XIX los cementerios estuvieron en manos de la Iglesia Católica. Por esta razón en ellos sólo se podían enterrar aquellas personas que profesaran la religión católica. La llegada de extranjeros no católicos a Costa Rica, se incrementó en la segunda mitad del siglo XIX y el fallecimiento de algunos de ellos provocó conflictos entre extranjeros y la Iglesia por la negativa de esta última a permitir el enterramiento de no católicos en los cementerios (Stephens, 2002: 58). La negativa de la iglesia para enterrar a un individuo extranjero en 1839 causó hasta un fuerte reclamo por parte del Jefe de Estado Braulio Carrillo, quien apeló a principios de humanismo y de tolerancia cristiana (Blanco, 1967: 292).

Esta fue una muestra de intolerancia religiosa por parte de la iglesia católica. En esta época Joaquín Bernardo Calvo hablaba de la necesidad de mantener una intolerancia teológica la cual se justificaba como necesaria ya que era una herejía el considerar que "todo hombre de bien, en cualquiera religión que viva de buena fe puede salvarse" (El Mentor Costarricense, 1843:119). En este sentido, se establecía que no debía de haber tolerancia, ya que esta destruiría la religión. Sin embargo, se establecía una tolerancia civil, independientemente de la religión que profesara el extranjero, la cual era necesaria sobre todo para el establecimiento de relaciones comerciales 
(El Mentor Costarricense, 1843: 119), en un contexto socioeconómico caracterizado por el desarrollo de la agricultura comercial del café, de la búsqueda de relaciones comerciales con distintos países, en especial con Europa y de la llegada cada vez mayor de inmigrantes.

No faltan los casos de extranjeros, quienes viendo cerca la muerte y conociendo la intolerancia teológica se declaran cristianos para ser enterrados sin contratiempos. Sin embargo, no pudieron prever la gran alegría que provocarían por ser infieles conversos (Stephens, 2002: 58-59), por lo cual sus funerales revistieron un carácter especial por la "conversión de un pecador". No fue sino hasta finales de la década de 1850, cuando el gobierno de Gran Bretaña presionó para que se creara un cementerio para protestantes.

\subsection{El establecimiento del cementerio protestante}

En el año 1850, se estableció un cementerio protestante a instancias del Encargado de Negocios inglés Sir Frederic Chatfield. Este se ubicó a un costado del cementerio católico en un terreno que el gobierno costarricense destinó para tal fin. En sus primeros años, fueron enterrados artesanos pobres, en cuyo entierro fungió como pastor el Vicecónsul inglés (Wagner y Scherzer, 1974: 235). El cementerio ocupaba cerca de la cuarta parte de un acre, estaba rodeado de un muro sencillo y una puerta de barras de hierro (Meagher, 2002: 239).

Pero ¿cómo puede explicarse esta concesión del gobierno de Costa Rica para crear un cementerio protestante? Esta concesión tenía un trasfondo económico y político. Después de la independencia en 1821, Costa Rica buscó un producto que la vinculara al mercado mundial. El cultivo del tabaco, la producción de caña de azúcar y la explotación minera fueron algunos intentos iniciales para lograr ese propósito. En la década de 1830, el café se impuso como el producto que insertó de manera definitiva la economía costarricense en el mercado internacional.

El inicio de la exportación regular a Inglaterra, en 1843, hizo que el financiamiento de la actividad se diera por medio de casas comerciales consignatarias británicas, especialmente de Londres y Liverpool (Araya, 1982: 30). Así, la Gran Bretaña era vista como la potencia mundial y el mercado actual y potencial del cual dependía, en gran parte, la prosperidad económica del país.

En este contexto, Costa Rica buscó por diversos medios durante la década de 1840 y especialmente de la 1850, un acercamiento más directo con Inglaterra, con la finalidad de establecer tratados bilaterales de amistad y comercio. La relación con Gran Bretaña llegó a tales extremos que incluso en 1848 Costa Rica quiso llegar a ser protectorado de su "Majestad Británica”.

Todo este juego político estaba dentro de las aspiraciones de las élites locales por participar aunque fuera de manera indirecta, de los beneficios de la Revolución Industrial. 


\subsection{La secularización de los cementerios}

Las reformas liberales de la década de 1880, específicamente la Reforma Jurídica de 1884, estableció la secularización de los cementerios, con lo cual en adelante estos ya no serían administrados por la Iglesia, sino por las municipalidades. Esta disposición se llevó a cabo con la finalidad de regular los enterramientos y generalizar el uso de los cementerios a todos los ciudadanos, evitando la exclusión de aquellos que no profesaban la religión católica.

Las reformas liberales fueron parte del proceso de consolidación del Estado Liberal. Aunque las ideas liberales habían permeado distintos ámbitos de la sociedad costarricense desde los primeros años de la independencia, no fue sino a partir de la década de 1880 en que tomaron forma como un cuerpo estructurado de leyes que, entre otras cosas, buscaba restar poder a la iglesia a nivel económico y político.

A parte de la secularización de los cementerios en esta década también fue cerrada la universidad de Santo Tomás, bajo administración de la iglesia católica, fuerte bastión del pensamiento conservador eclesiástico; se estableció la laicización de la enseñanza, el Código Civil y por ende el matrimonio civil y el divorcio que afectaban sensiblemente las ideas católicas.

Si bien, desde la independencia política de Costa Rica en 1821, se da una estrecha relación entre la iglesia y el estado al establecerse que la religión del Estado era la Católica (Blanco, 1967: 285287), el desarrollo de la agricultura comercial por medio de la producción y exportación de café, provocó también un intercambio cultural que motivó la llegada de nuevas ideas vinculadas con el liberalismo, lo que hizo tensas las relaciones entre la Iglesia y el Estado.

En la década de 1880 la iglesia perdió el control sobre los cementerios, como producto de una apertura paulatina hacia la tolerancia religiosa y la intervención del estado en áreas civiles. Si bien, los ritos funerarios en su conjunto no variaron sensiblemente, en los cementerios, antes lugares sagrados solo para católicos, se incorporaron enterramientos de individuos de distintos credos o sin credo alguno. Los nichos se convirtieron en estructuras mediáticas para expresar distinciones sociales y sufrieron la influencia arquitectónica de tendencias como el neoclasicismo.

\section{Comentarios finales}

Los ritos funerarios en su conjunto no variaron sensiblemente durante el siglo XIX. Los principales cambios se dieron con la reubicación de los cementerios fuera de los terrenos de las iglesias (1814), la construcción del cementerio protestante (1850) y la secularización de los cementerios (1884).

Después de 1814 los nichos se convirtieron en el medio utilizado por la elite para hacer evidentes las diferencias sociales dentro de un "área común" de enterramiento.

La iglesia católica ayudó a reforzar esta diferenciación social al aliarse con los grupos socioeconómicos por medio de una participación activa en los ritos funerarios, participación que 
a la iglesia le generaba importantes dividendos por el pago de sus servicios religiosos. Era una alianza del poder socioeconómico seglar con el religioso.

Por otra parte, los pobres fueron discriminados por parte de la iglesia al condicionar la participación religiosa al pago de derechos por la ejecución bendiciones, acompañamientos del cortejo al cementerio, pago de derechos de enterramiento y las misas. Pero, además, todo su ritual se convirtió en una manifestación más de la diferenciación socioeconómica de la sociedad costarricense.

A pesar de lo anterior, partes del rito funerario como el traslado del sacerdote para aplicar la extremaunción a un enfermo grave, el cortejo fúnebre, los rezos por el alma del difunto y las necrologías reforzaban el significado de compartir el dolor con la comunidad y reclamaban comprensión social. En este sentido, la muerte era un acontecimiento público que la sociedad necesitaba cicatrizar.

\section{Referencias bibliográficas}

Araya Pochet, C. (1982). Historia económica de Costa Rica (1821-1971).

San José: Editorial Fernández Arce.

Archivo Nacional de Costa Rica (s.f.).Álbum de Figueroa. Folios: 25, 26, 27.

Barros Arana, D. (1911).Obras Completas. Estudios histórico-bibliográficos. Santiago, Chile: Imprenta Cervantes. Tomo X.

Blanco Segura, R. (1967). Historia eclesiástica de Costa Rica. Del descubrimiento a la erección de la Diócesis (1502-1850). San José: Editorial Costa Rica.

Cementerio General de San José. (2005). Disponible en:

http://www.jps.go.cr/JPS/PageCreator/paginas/cementerioGeneralnew.htm.[Consultado el 28 de setiembre]

El Mentor Costarricense. (1843). 2 setiembre. p. 119.

----. (1843). 25 noviembre. $\mathrm{N}^{\circ} 37$. p. 143.

----. (1845). 21 noviembre. $\mathrm{N}^{\circ} 16$. tomo $2^{\circ}$.p. 61.

Fernández, L. (1976). "Don Tomas de Acosta informa al Presidente de Guatemala sobre pompas fúnebres y toques de campanas en la ciudad de Cartago. Año 1801”. En: Asentamientos, Hacienda y Gobierno. San José: Editorial Costa Rica. Vol. III. pp. 180-183.

González Ortega, A. (1996). Vida cotidiana en la Costa Rica del siglo XIX. San José: Editorial Costa Rica. 
Marr, W. (2002)."Viaje a Centroamérica”. En: Fernández, R.: Costa Rica en el siglo XIX. Antología de Viajeros. San José: EUNED. pp. 95-210

Meagher, T.F. (2002). "Vacaciones en Costa Rica”. En: Fernández, Ricardo: Costa Rica en el siglo XIX. Antología de Viajeros. San José: EUNED. pp. 271-369

Molina, I. (1991). Costa Rica (1800-1850). El legado colonial y la génesis del capitalismo. San José: Editorial de la Universidad de Costa Rica.

Payne, E., C. Vargas y C. Velásquez. (1992). Breve Historia de la Iglesia Católica en Costa Rica (1502-1992). Escuela de Historia y Geografía, Centro de Investigaciones Históricas. San José: UCR.

Sacramentos. (2005). Disponible en: http://www.enciclopediacatolica.con.htm. [Consultado el 3 de octubre]

Stephens, J.L. (2002). "Incidentes de viaje en Centroamérica, Chiapas y Yucatán". En: Fernández, R.: Costa Rica en el siglo XIX. Antología de Viajeros. San José: EUNED. pp. 33-78.

Vázquez, R., T. Hidalgo y F. Sol. (1999). "Rescate arqueológico en el sitio La Catedral Metropolitana de San José”. Vínculos .24 (1-2). pp. 53-84.

Velásquez, C. (1996). "Morir en el siglo XVII”. Revista de Historia. San José. $\mathrm{N}^{\circ}$ 33. pp. 45-66.

Wagner, M. y C. Scherzer. (1974). La República de Costa Rica en la América Central. San José: Ministerio de Cultura Juventud y Deportes. Tomo 1. 